\title{
Fostering Student Engagement: Creative Problem-Solving in Small Group Facilitations
}

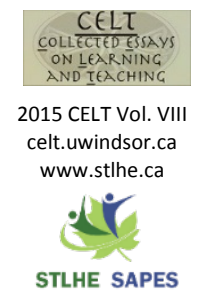

\author{
Patricia L. Samson \\ University of Windsor
}

Creative Problem-Solving (CPS) can be a transformative teaching methodology that supports a dialogical learning atmosphere that can transcend the traditional classroom and inspire excellence in students by linking real life experiences with the curriculum. It supports a sense of inquiry that incorporates both experiential learning and the development of critical thinking skills. Incorporating active learning strategies in a way that transcends the classroom and sparks interest and passion for students is an important pedagogical ingredient for educators. The key question driving this study is how can CPS as a teaching method be used to motivate students and engage them in a process of active learning within the context of a social policy course? This study examines student engagement and motivation in a problem-centred approach to teaching and learning, and provides a concrete example of a CPS exercise couched in small group facilitations to support peer learning.

\section{Introduction}

C reative Problem-Solving (CPS) is a powerful teaching method that can support a pedagogical shift in the classroom and foster both student engagement and motivation to learn. Caswell (2006) describes it as an approach to finding workable answers to problems that exist in real life. Treffinger, Selby and Isaken (2008) define CPS as a 'wellestablished circular framework involving four central components that include: understanding the challenge, generating ideas, preparing for action and planning the approach' (p. 392). Treffinger et al. (2008) view CPS as a systematic process involving linkages among the characteristics of both the individuals involved in the creative problem-solving process as well as the environment in which it occurs. Key influences on this process include a person's way of processing information, how decisions are made, and the person's perspective toward change (Treffinger et al., 2008). In CPS, participants work in groups to creatively solve a task or situation that is based in reality, but generally has no known or predetermined solution (Caswell, 2006).

CPS as a teaching method incorporates active learning strategies to engage students in working with complex situations. The overarching question for this study is "how can Creative ProblemSolving as a teaching method be used to motivate students and engage them in a process of active learning within the context of a challenging social policy course?" To answer this question, student engagement and motivation for learning will be examined and then linked to CPS as a teaching strategy by highlighting a specific example in a course through a small-group facilitation assignment. 


\section{Student Engagement in Learning}

This concept of student engagement has risen to the forefront in the arena of teaching and learning, where a trend of decreasing levels of satisfaction in education has been identified (Delialioglu, 2011). Robinson and Hullinger (2008) describe student engagement as an important factor in the quality of education students are receiving. The more students are engaged in the classroom, the more willing they are to actively participate and contribute to an effective learning environment. Additionally, the more students' believe the course work is 'interesting and important', the more motivated and engaged they are in the learning process (Pintrich \& DeGroot, 1990). Thus, students' engagement in learning and their sense of satisfaction in this process can be seen as being reciprocal. Factors identified as ways to promote student satisfaction include the addition of activities that capture students' attention, are relevant to their goals and needs, and promote confidence that they can be successful in the course (Goldberg \& Ingram, 2011).

Student engagement has been defined as 'efforts of the student to study a subject, practice, obtain feedback, analyze and solve problems' (Robinson \& Hullinger, 2008, p. 101). Delialioglu (2011) defines student engagement as a process that involves students in activities that are considered 'academically meaningful' that contribute to both learning and personal development. A key way to engage students is to incorporate active learning strategies into the curriculum (Delialioglu, 2011; Goldberg \& Ingram, 2011; Hayden, Ouyang, Scinski, Olszewski, \& Bielefeldt, 2011). Studies that look at the concept of student engagement find that

- teaching practices that incorporate active learning activities are positively related to levels of engagement

- instructional environments and practices influence student motivation and engagement
- there are multiple and varying indicators and measures for student engagement

- activities targeting higher-order cognitive skills promote engagement

- engagement increases with multiple and varied forms of interaction between teachers and students

- increased student interest in an assignment promotes deeper levels of thinking

- activities involving collaborative investigations and incorporate activities such as observation, guided inquiry, socialization and interaction with experts, peers and teachers enhance student engagement in learning (Delialioglu, 2011; Dixson, 2010; Goldberg \& Ingram, 2011; Hayden et al, 2011; Robinson \& Hullinger, 2008).

These key findings are further supported by what are referred to as the "Seven Principles of Good Practice in Undergraduate Education" which include increased interaction between teacher and student, opportunities for allowing students to work cooperatively, utilization of active learning strategies, timely student feedback, requirements for students to spend time working on academic tasks, having high standards for academic work, and teaching that recognizes different learner needs (Delialioglu, 2011; Robinson \& Hullinger, 2008).

It is important for teachers to integrate active learning strategies into the classroom in order to effectively engage students in the learning process. Dixson (2010) suggests that increased and multiple forms of communication and interaction between teachers and students may be connected to higher levels of engagement. An important component to student engagement is the concept of motivation for learning, of which self-directed learning is an essential consideration. Self-directed learning is an essential component for problem-centred approaches to learning and captures the ingredients necessary to motivate and engage students in the learning process. 


\section{Self-directed learning and student motivation}

Self-directed learning has been defined as 'a process in which individuals take the initiative in diagnosing their learning needs, formulating learning goals, identifying human and material resources for learning, choosing and implementing appropriate learning strategies and evaluating learning outcomes' (Knowles, 1975, p. 18). Students assume ownership of their learning and thus have an increased commitment to their overall education and related academic achievements.

Central components of theories related to adult learning principles revolve around the concepts of self-actualization, motivation and self-directed learning. Self-actualization is described as a sense of realizing one's full potential (Maslow, 1954). According to Marquardt and Waddill (2004), the humanist perspective sees a person looking to achieve self-actualization through learning and embraces the concept of self-directed learning to achieve that full potential. The key principles of adult learning include a need to know the why of learning, motivation for learning and solving problems, building upon/incorporating prior experience, matching learning approaches to the diverse backgrounds of adult learners, and active involvement in the learning process (Bryan, Kreuter, \& Brownson, 2009; Knowles, 1975; Knowles, Holton, \& Swanson, 1998; Welty, 2010). Welty (2010) suggests that experience is the most salient feature for adult learners, as it generates needs, interests and motivation to engage in learning.

These principles combine to inform the process of self-actualization and self-directed learning for adults. The role of the teacher in this process is that of a facilitator (Knowles et al., 1998). Adult learning theories combine tenets of both the humanist and behavioural learning theories in terms of self-directed learning being influenced by a student's "readiness to learn", which was originally put forth by Thorndike (1932) from the behaviourist perspective of rules which govern the learning process. The concept of readiness to learn has been linked to student motivation for learning (Pintrich \& DeGroot, 1990) and is an important consideration when looking at the process of engaging students in active learning.

These core principles of adult learning encapsulate the social context of learning and the construction of knowledge through dialogic interaction. Constructivists posit that knowledge is bound to the context, and people make meaning of their experiences through a process of constructing their own reality (Marquardt \& Waddill, 2004). According to Schunk (1996), constructivist approaches to learning share some components with cognitive and behavioural theories and emphasize the social context of learning through such mechanisms as collaborative group work, peer feedback and dialogic interactions.

The key tenets of constructivist learning theory are that knowledge is built from within by thinking, social interaction is important in the construction of knowledge, the nature of cognition is functional and adaptive, and the purpose of cognition is to help people organize their experience of the world (Cakin, 2008). People need to integrate new information with prior knowledge in order to promote deep learning (Vogel-Walcutt, Gebrim, Bowers, Carper, \& Nicholson, 2011). Within this framework, Creative Problem-Solving as a teaching methodology supports these processes. Planning learning activities for students that incorporate the key principles of adult learning is critical to an effective course design that promotes deep learning and the attainment of threshold concepts.

A review of the literature identifies a shift in pedagogy and viewing students as passive recipients of knowledge, or what Friere (1970) referred to as 'empty vessels,' to active participants in the learning process. The term Self-Regulated Learning has been used to describe 'self-directed learning processes and beliefs that allow learners to transform their mental abilities' (Zimmerman, 2008, p. 166). According to Pintrich and DeGroot (1990), self-regulated learning involves metacognitive strategies that students use to learn, recall and understand course material. It involves strategies that foster 'cognitive engagement' in the learning process that can increase the levels of 
achievement for students (Pintrich and DeGroot, 1990). All of these processes can be brought to life through CPS and enhanced when incorporated into a small-group facilitation assignment for students.

In the field of social work, social policy analysis is considered a difficult course. Many students are focused on clinical pursuits, so recognizing the relevance and impact of the overarching legislative and procedural context of practice can be challenging. Social policy can at times be viewed in a similar vein as statistics, which can generate anxiety for some students. A problemcentred approach to teaching and learning in this light can aid students embarking on a social policy analysis project to develop the necessary skills in problem identification, research, critical analysis and synthesis of information to make effective policy change recommendations to address social issues impacting vulnerable populations in our society. The added layer of facilitating small peer group discussions and engaging them further in the problem-solving process helps promote deeper learning for these students by incorporating group work that mirrors what could happen in the real world.

The task for teachers lies in engaging those students who may be resistant to active learning, preferring the "traditional" education model that displays Friere's (1970) banking concept of education. Some research studies related to student motivation for learning suggest that students who believe they are capable engage in more metacognition, use more cognitive strategies that include things such as rehearsal, elaboration and organizational strategies, and are more likely to keep working at a task than students who do not believe they can do the work (Pintrich, 2003; Pintrich \& DeGroot, 1990).

Teachers face an ongoing challenge of encouraging students to be active and motivated learners. Research pertaining to student motivation to learn demonstrates that the motivational beliefs of students have a direct influence on academic performance (Paulsen \& Feldman, 1999; Pintrich, 2003; Pintrich \& DeGroot, 1990). According to Paulsen and Feldman (1999), students' epistemological beliefs impact their motivation, the cognitive strategies they use, and the learning outcomes that will be achieved. Finding mechanisms to tap into these beliefs may be an entry point for enhancing a student's motivation to engage in active learning within the classroom, and CPS is one way to achieve this.

\section{CPS as a way to promote student engagement and motivation}

Problem-solving activities within the classroom have been found to be effective mechanisms to engage students in active learning. According to Yen and Lee (2011), problem-solving activities shift the focus of the class to a student-centred orientation, which provides the setting for students to engage in more creative and interactive ways. These problem-solving activities in a course give students the chance to build needed skills in working collaboratively with their peers (Memory, Yoder, \& Williams, 2003) and this process of collaborative learning has been associated with increased levels of course satisfaction among students (So \& Brush, 2008).

Shea and Bidjerano (2010) note that group settings support the construction of knowledge through the social interaction opportunities that these types of forums present and the negotiation that occurs within the group processes. In a study assessing the impact of Problem Based Learning (PBL) in a large classroom setting, Klegeris, Bahniwal and Hurren (2013) found a 13\% increase in the test scores of those students who were taught PBL when compared to those who had not received this instruction. A central tenet of PBL is the context of the problem being addressed and one of the main advantages of this instructional method over what might be considered a more traditional classroom model is the ability for students to develop skills in problem-solving, though the overall effectiveness and transferability of these skills is still a question under debate (Klegeris et al., 2013).

According to Delialioglu (2011), active learning strategies, student work that incorporates 
collaboration to address tasks that are challenging, and timely feedback help increase both learning and academic achievement. In a study assessing student engagement in blended learning environments that included PBL and lectures, findings indicated that levels of student engagement were significantly higher in the Problem Based Learning portions of the course (Delialioglu, 2011). While being identified as something that is difficult to define, PBL has been identified as a type of experiential learning in "real life" situations and is reported to help students engage in an active learning process (Hmelo-Silver, 2004). Pease and Kuhn (2011) noted that a key feature of this approach to learning is the contextualization of learning via a problem that is presented to students who have no prior preparation on the topic. Generally, the problem is both the stimulus and context for learning, where small groups of students are given a problem to address by identifying what they need to determine a course of action to solve the problem (Hmelo-Silver, 2004; Parton \& Bailey, 2008; Pease \& Kuhn, 2011). According to HmeloSilver (2004), students formulate and analyze the problem assigned, gain an understanding and generate hypotheses surrounding possible solutions, and identify areas where knowledge is lacking relative to the problem; these gaps in knowledge then become the focus of the student self-directed learning process. Creative Problem-Solving, as a teaching methodology that incorporates these components of Problem Based Learning but going well beyond, can be seen as an effective way to engage students in learning.

\section{The Key Components of Creative Problem-Solving}

Small group formats have been shown to promote learning for students, and findings from a metaanalysis on this topic by Springer, Stanne and Donovan (1999) indicated that different forms of small group learning activities are effective in generating improved academic achievement and more positive attitudes toward learning overall for students. Small group forums allow students to develop value in the work of the group, support peer learning, aid in holding members accountable, and enable regular assessment of progress toward group goals, all of which influence the overall motivation for group members to achieve their goals (Springer et al., 1999). This social interaction between members in a group project provides a venue to create and enhance motivation for students who are participating and learning in this process (So \& Brush, 2008). Creative Problem-Solving is one type of group activity that incorporates a problem-centred approach to learning for students that integrates those components of collaborative learning, problem-solving skills, dialogic interaction, and the social construction of meaning through group processes that can bring a subject within the context of course to life for students who are participating in this process.

To reiterate a brief definition of CPS, it is described as a group problem-solving process that addresses "wicked" problems in the real world (Caswell, 2006; Treffinger et al., 2008). Wicked problems are viewed as real, unsolved problems that have no known nor pre-set answers; they are considered to be 'vague' and require 'creativity' to resolve them (Caswell, 2006). As noted by Caswell (2006), in CPS, the real problem may not even be known or clear at the start and may emerge through the process of trying to solve an issue. Caswell (2006) identifies three triads related to Creative ProblemSolving that are seen as revolving around the concept of wicked problems. The first triad identified is the Fundamental Triad which includes familiarization, where students start to develop an awareness of the problem they are working on resolving; functionality, that involves clarifying the real issue to be addressed and how to proceed with its resolution; and testing, where effectiveness of the proposed solution is examined (Caswell, 2006). The second triad is identified as Harmonizing Structure, which encompasses the tools of communication, visualization, and collaboration in understanding the problem and generating possible solutions to address it (Caswell, 2006). The third triad, Theoretical Environment incorporates the concepts of narrative, participation, and inquiry in telling the story and engaging students in creating new knowledge in 
developing unique solutions to the problems posed (Caswell, 2006). The role of the student in this process is one of active participation where personal assumptions and biases can be challenged and the views of others can be acknowledged and considered in the problem-solving process; students come together and work collaboratively toward resolutions of problems or issues (Caswell, 2006).

Within this framework teachers need to move beyond the traditional classroom and take on the role of facilitator and coach to encourage students to participate in knowledge creation through the problem-solving process (Caswell, 2006). According to Caswell (2006), teachers need to work at drawing out the knowledge and experience students bring with them and support a safe atmosphere in the classroom that allows students the ability to explore and develop their own resolutions. Such an approach fosters those central tenets of both the humanist and constructivist learning theories, combined with key components of Problem Based Learning and supported within a framework of experiential learning, that are all operationalized in the classroom through this specific teaching methodology.

\section{Incorporating experiential learning}

According to Kolb (1984), learning is best generated in an atmosphere where there is a dialectic tension and conflict that can promote a learning environment through a process of inquiry and understanding. Experiential learning theory has been described as a practice theory that combines 'experience, perception, cognition and behaviour' (Kolb, 1984, p. 21). The centrepiece of Kolb's (1984) theory of experiential learning is the identification of four modes of learning through which new knowledge, skills or attitudes are achieved. These modes include concrete experience, reflective observation, abstract conceptualization, and active experimentation (Kolb, 1984). Kolb (1984) describes the learning process as a holistic cycle that integrates all of these components. The acquisition of knowledge is viewed as a transformative process that is continually being recreated (Kolb, 1984; Mezirow, 1990) in this learning cycle. These key components of experiential learning can be brought to life through the process of students engaging in a Creative Problem-Solving exercise within the classroom.

Experiential learning is a key ingredient that is incorporated into the context of many professional programs of higher education, including fields such as social work, nursing, medicine and education, to aid in the development of skilled practitioners. It supports the use of critical reflection in practice and contributes to the learning environment for students, particularly as it relates to the field practicums, internships and residencies in professional education programs. This is the realm that combines theory to practice and may be the most appropriate environment to assess the level and capacity of students to think critically.

Problem-centred learning activities, such as CPS, can provide students with opportunities that are based in reality and promote processes that include 'active exploration and knowledge sharing among the participants' (Yen \& Lee, 2011, p. 139). Yen and Lee (2011) identify four major pieces involved in the process of problem solving and these include resources, heuristics, control in relation to these two components, and beliefs. For teachers, part of the process needs to include spending time in class to explicitly go over the knowledge and skills needed to engage in working collaboratively with peers to solve problems (Memory et al., 2003). This work will help frame an assignment for a course that incorporates a group problem-solving process as a major component to successfully complete the course requirements. The role of the teacher as facilitator and coach is an important ingredient in framing problem-centred learning activities within the classroom, and teacher presence in collaborative group experiences has been shown to demonstrate a positive relationship to improved self-efficacy and cognitive presence for students (Shea \& Bidjerano, 2010). So and Brush (2008) also found that a feeling of connection that is generated in collaborative learning activities positively affects students' motivation. Collaborative learning activities increase students' interactions with each other, and indications are that this allows for more dialogue, interaction and engagement in a course (So 
\& Brush, 2008). Hence, collaborative problemsolving activities within a course can promote active engagement and motivation to learn among students.

Through a problem-centred approach to learning, students are given a forum to generate knowledge through a process of negotiating meaning with others in their group (So \& Brush, 2008). According to Memory et al. (2003), students tend to work better on problem-solving activities when they are involved in choosing the problem the group is going to work on. They also report that students then are able to give enhanced presentations on their own group projects and are better able to apply the skills they have learned in new activities moving forward (Memory et al., 2003). In this vein, Creative Problem-Solving can be integrated into a small group facilitation process for students, where they can discover and implement new skills in working through a real life problem scenario in a specific course.

\section{Sample assignment: small group facilitation}

In order to better conceptualize how CPS can operate within the context of a specific course, a practical example is described in what follows. The example is framed within a Social Policy Analysis course in the field of social work and outlines the purpose, key learning outcomes and a sample grading rubric. The purpose of the assignment is to aid students in learning about social policy analysis and develop skills in the assessment and recommendation of changes in current policies, programs or services to meet the needs of vulnerable people in our society.

\section{CPS assignment: in groups of 3-5}

\section{Students will:}

- Identify a social problem facing a vulnerable population and the social policy response currently in place to address this issue.
- Pose a "wicked problem" in relation to the issue identified, and engage as a group in the problem-solving process to develop unique solutions to the problem posed

- Facilitate a 60 minute small group discussion with their peers in class on the social issue they have chosen, providing an overview of the issue and current/related policy response to set the stage for the group dialogue to follow

- Facilitate the group discussion in class by using thoughtful questions based on their scholarly research, critical analysis and incorporation of course readings and concepts, with an aim to engage their classmates in further problem-solving activities to generate more possible solutions to the original social problem identified

- Be encouraged to be creative and integrate life experience and current events as they facilitate this process with their peers, to ground the learning from this assignment.

\section{Learning Outcomes}

Upon successful completion of this assignment, students will be able to:

- Identify relevant social issues and problems impacting vulnerable populations in society

- Express their own thoughts, feelings, values and judgements in an atmosphere that incorporates respect for the diversity of all students participating in the group process

- Critically analyze the social problem identified, integrate course concepts and generate possible solutions by applying the knowledge and skills learned through a collaborative group problem-solving process

- Synthesize all of the information and experiences of the group process and facilitate a group discussion with the class that integrates the key issues and possible solutions 
This assignment engages the students in active learning through the process of Creative Problem-Solving in bringing this assignment to life. It is meant to cover the entire semester in order to allow sufficient time for students to thoroughly investigate their issues. Students have time allotted in class each week to work on the project, allowing time and space for both peer and teacher feedback over the entire course. The assignment requires that students move through a series of scaffolded learning components where the students in a small group first identify the social issue to be addressed, define the problem and engage in research and a critical analysis to determine possible courses of action to address the social issue, and achieve a sense of problem resolution, to the extent that is possible with wicked problems.

In line with the triads of CPS, the first phase of identifying the social problem captures the essence of the Fundamental Triad, where students become familiar with the social problem. They engage in a critical analysis of all of the factors that are contributing to the problem, clarifying the issues and how they are impacting the identified vulnerable population. The students then start to test out possible solutions to resolve the problem. Activities students can engage in during this phase include conducting a comprehensive needs assessment of the community involved that identifies assets, barriers and gaps. Students can also spend time getting to know the people being affected by the problem and asking their perspective on what could or should be done. This process allows students to develop an accurate and authentic picture of all of the issues involved.

Students are encouraged and supported by the instructor and their peers to employ tools such as concept mapping to visualize the various aspects of the issue, consult those impacted by the problem (narrative), examine societal responses and challenges, and ultimately put forth a possible solution. This work captures the second triad of CPS, the Harmonizing Structure. In the processing of assessing the needs of the community involved in the problem, group members are supported by both their peers in the group process and the teacher in mapping out all of the factors that need to be considered in order to recommend solutions. Tools such as concept maps, logic models or other visual representations can serve as effective mediums to organize and categorize large amounts of information. The narrative stories of the people impacted directly by the social problem can serve to enhance this process and builds in that component of reality in allowing voice to those most directly affected. This can aid students in developing relevant skills in working with people, which is an essential ingredient for professional social work practice. Students can also consult with City or Provincial agencies to determine overarching societal responses. All of these pieces will help inform the possible solutions that the group will create.

The third triad of CPS, Theoretical Environment, that incorporates the concepts of narrative, participatory and inquiry, is enacted by the group when they engage with the larger class in conducting the small group facilitation. This is where the group will highlight their work: identifying the issue, incorporating their critical analysis, synthesizing the material, and then engaging their classmates in further exploration of possible solutions. Rather than just providing a brief power point presentation to the class on their own experience with this exercise, the group of students are then expected to facilitate the learning of their classmates on this identified social issue using a similar problem-solving process. This subsequent small group facilitation in class allows the students to expand this process to the classroom setting where the group can then engage their peers in this creative problem-solving process to identify further possible resolutions to the social issue or problem identified. It infuses an active learning process into the classroom and fosters ingenuity and creativity for the students, enhancing their motivation through an interactive, dialogical exchange that promotes deep learning, critical reflection and critical thinking. Students engage in working with course concepts with one another and model what the problem-solving process would look like if they were working as social workers in a community agency who were tasked with resolving a social problem for a vulnerable group of clients. This interactive process embodies those concepts of collaborative inquiry within a constructivist paradigm 
and can support students in challenging their assumptions and prior experiences to come up with new ways of seeing things. This whole process of CPS can be an effective strategy to weave in the concepts of experiential learning and promote the development of critical and reflective thinking skills that can transcend the classroom and help prepare students for the real world.

\section{A student's experience of CPS}

CPS as a mechanism for learning was powerful for this author, who experienced it as a student in a course on Learning-Centred Teaching in Higher Education. Students were tasked with forming small groups to learn about a specific teaching method that we then had to implement in class with our peers. This assignment was tremendously challenging and the most difficult task proved to be generating a wicked problem. The group members came from a variety of backgrounds and disciplines that brought in multiple perspectives, which made the process of achieving consensus on a specific problem to focus efforts on quite difficult. The actual process of each member articulating their perspective, conducting a scholarly review of the literature, and then engaging in planning and negotiation to map out an approach to solve the problem actually allowed the key issue to emerge. Group consensus on the problem to be addressed was established, that allowed a sense of ownership to grow, as well as a commitment among group members to develop solutions to mitigate the problem. The real learning came from the fact that the group owned both the problem and the subsequent process to resolve it. The instructor did not impose the problem on the group, but rather it emerged through group dialogue, exploration and research on the problem.

This approach to teaching demonstrates those key features of problem-centred learning that support the key principles of adult learning and engage students in a learning experience that goes well beyond a standard research project and served as the precursor to the creation of this Social Policy Project that incorporates a small group facilitation in a Social
Policy Analysis course for social work students in this current study. CPS creates a learning scenario that draws on group dynamics, creativity, and collaboration in shaping both the problem and solution. Adding in group facilitation allows students to share their learning with their peers in a way that further engages the class in a collaborative learning community. It is a unique learning experience that can help students develop tangible skills needed in the process of social policy analysis, including skills in problem identification, scholarly research, collaboration, advocacy, brokerage, critical analysis and the integration of practical solutions and recommendations to complex issues and problems.

\section{Conclusion}

Strategies that engage and motivate students promotes deeper learning and fosters the development of effective problem solving and critical thinking skills. In addressing the overarching question posed at the beginning of this paper, Creative Problem-Solving is an effective teaching method to motivate and engage students in learning. It provides a forum to integrate real world experiences into the classroom setting and serves as a mechanism to engage students in an authentic learning process. Specific strategies that target scaffolded learning, incorporation of visual concept maps, storytelling, and social inclusion through the group experience for all students in the class serve to strengthen this experience.

Teachers need to find ways to incorporate active strategies in a way that sparks interest and passion for students. Incorporating a constructivist framework that supports such an approach may be a solution, along with the preparatory work in readying students to engage in such a pedagogical shift, as in some disciplines this teaching method may be considered outside of the norm of what is expected for some students in the classroom setting. A key role for teachers lies in helping students prepare for and embrace a change in teaching and learning approaches, to tap into that engagement concept and 
spark some of that interest and motivation to learn in a course that can be considered difficult or challenging, such as a social policy analysis course. A research agenda that focuses on the pedagogy to support such a shift may be of merit. Creative Problem-Solving as a teaching methodology, in support of learning-centred teaching in a variety of contexts that embraces ambiguity and challenge, may be a starting point for such an agenda, particularly as it relates to the transferability of these problemsolving skills learned in the classroom to the real world environment.

\section{References}

Bryan, R. L., Kreuter, M. W., \& Brownson, R. C. (2009). Integrating adult learning principles into training for public health practice. Health Promotion Practice, 10, 557-563. http://dx.doi.org/10.1177/1524839907308 117

Cakin, M. (2008). Constructivist approaches to learning in science and their implications for science pedagogy: A literature review. International Journal of Environmental \& Science Education, 3, 193-206. Retrieved from http://www.ijese.com/V4N4.htm

Caswell, D. (2006). Creative problem-solving. London: Society for Teaching and Learning in Higher Education.

Delialioglu, O. (2011). Student engagement in blended learning environments with lecturebased and problem-based instructional approaches. Educational Technology \& Society, 15(3), 310-322.

Dixson, M. D. (2010). Creating effective student engagement in online courses: What do students find engaging? Journal of the Scholarship of Teaching and Learning, 10(2),
1-13. Retrieved from http://josotl. indiana.edu/article/view/1744/1742

Friere, P. (1970). Pedagogy of the oppressed. New York: The Continuum International Publishing Group.

Goldberg, N. A., \& Ingram, K. W. (2011). Improving student engagement in a lowerdivision botany course. Journal of the Scholarship of Teaching and Learning, 11(2), 76-90. Retrieved from http://josotl. indiana.edu/article/view/1819

Hayden, K., Ouyang, Y., Scinski, L., Olszewski, B., \& Bielefeldt, T. (2011). Increasing student interest and attitudes in STEM: Professional development and activities to engage and inspire learners. Contemporary Issues in Technology and Science Teacher Education, 11(1), 1-22. Retrieved from http://www.cite journal.org/vol11/iss1/science/article1.cfm

Hmelo-Silver, C. E. (2004). Problem-based learning: What and how do students learn? Educational Psychology Review, 16, 235-266. http://dx.doi.org/10.1023/B:EDPR.000003 4022.16470.f3

Klegeris, A., Bahniwal, M., \& Hurren, H. (2013). Improvement in generic problem-solving abilities of students by use of tutor-less problem-based learning in a large classroom setting. CBE-Life Sciences Education, 12, 7379. http://dx.doi.org/10.1187/cbe.12-060081

Knowles, M. S. (1975). Self-directed learning: A guide for learners and teachers. Chicago, Illinois: Follett Publishing.

Knowles, M. S., Holton, E. F., \& Swanson, R. A. (1998). The adult learner ( $5^{\text {th }}$ ed.). Houston, TX: Gulf Publishing Company. 
Kolb, D. A. (1984). Experiential learning: Experience as the source of learning and development. Englewood Cliffs, NJ: Prentice-Hall.

Marquardt, M., \& Waddill, D. (2004). The power of learning in action learning: A conceptual analysis of how five schools of adult learning theories are incorporated within the practice of action learning. Action Learning: Research and Practice, 1, 185-202. http://dx.doi .org/10.1080/1476733042000264146

Maslow, A. H. (1954). Motivation and personality. New York: Harper \& Row, Publishers.

Memory, D. M., Yoder, C. Y., \& Williams, R. O. (2003). Using problem-centred learning for teaching collaboration in a general methods course. The Clearing House, 77, 67-72. http://dx.doi.org/10.1080/0009865030960 1231

Mezirow, J. (1990). Fostering critical reflection in adulthood. San Francisco, CA: Jossey-Bass.

Parton, G. \& Bailey, R. (2008). Problem-based learning: a critical rationalist perspective. London Review of Education, 6, 281-292. http://dx.doi.org/10.1080/1474846080252 8475

Paulsen, M. B. \& Feldman, K. A. (1999). Student motivation and epistemological beliefs. New Directions for Teaching and Learning, 1999(78), 17-25. http://dx.doi.org/10. $1002 / \mathrm{tl} .7802$

Pease, M. A., \& Kuhn, D. (2011). Experimental analysis of the effective components of problem- based learning. Science Education, 95, 57-86. http://dx.doi.org/10.1002 /sce. 20412

Pintrich, R. P. (2003). A motivational science perspective on the role of student motivation in learning and teaching contexts. Journal of
Educational Psychology, 95, 667-686. http://dx.doi.org/10.1037/0022-0663.95.4. 667

Pintrich, P. R., \& DeGroot, E. V. (1990). Motivational and self-regulated learning components of classroom academic performance. Journal of Educational Psychology, 82, 33-40. http://dx.doi.org/ 10.1037/0022-0663.82.1.33

Robinson, C. C., \& Hullinger, H. (2008). New benchmarks in higher education: Student engagement in online learning. Journal of Education for Business, 84, 101-109. http://dx.doi.org/10.3200/JOEB.84.2.101109

Schunk, D. H. (1996). Learning theories: An educational perspective. Englewood Cliffs, NJ: Merrill.

Shea, P., \& Bidjerano, T. (2010). Learning presence: Towards a theory of self-efficacy, selfregulation, and the development of a communities of inquiry in online and blended learning environments. Computers \& Education, 55, 1721-1731. http://dx.doi.org/10.1016/j.compedu.2010. 07.017

So, H-J., \& Brush, T. A. (2008). Student perceptions of collaborative learning, social presence and satisfaction in a blended learning environment: Relationships and critical factors. Computers \& Education, 51, 318336. http://dx.doi.org/10.1016/j.compedu. 2007.05.009

Springer, L., Stanne, M. E., \& Donovan, S. S. (1999). Effects of small-group learning on undergraduates in science, mathematics, engineering, and technology: A metaanalysis. Review of Educational Research, 69, 21-51. http://dx.doi.org/10.3102/003465 43069001021 
Thorndike, E. (1932). The Fundamentals of Learning. New York: Teachers College Press.

Treffinger, D. J., Selby, E. C., \& Isaken, S. G. (2008). Understanding individual problemsolving style: A key to learning and applying creative problem-solving. Learning and Individual Differences, 18, 390-401. http://dx.doi.org/10.1016/j.lindif.2007.11. 007

Vogel-Walcutt, J. J., Gebrim, J. B., Bowers, C., Carper, T. M., \& Nicholson, D. (2011). Cognitive load theory vs. constructivist approaches: Which best leads to efficient, deep learning? Journal of Computer Assisted Learning, 27, 133-145. http://dx.doi.org/ 10.1111/j.1365-2729.2010.00381.x

Welty, G. (2010). Effective training reader Q\&AWhat are adult learning principles? Journal of GXP Compliance, 14, 8-19.
Yen, J. C. \& Lee, C. Y. (2011). Exploring problem solving patterns and their impact on learning achievement in a blended learning environment. Computers \& Education, 56, 138-145. http://dx.doi.org/10.1016/j.comp edu.2010.08.012

Zimmerman, B. J. (2008). Investigating selfregulation and motivation: Historical background, methodological developments, and future prospects. American Educational Research Journal, 45, 166-183.

\section{Biography}

Patricia L. Samson is a PhD Candidate and Sessional Instructor at the University of Windsor. Her research focuses on social work education, and teaching and learning in higher education more generally.

\section{Appendix Assessment/Evaluation of CPS assignment}

\begin{tabular}{|c|c|}
\hline During the Presentation (Beginning) & Grade \\
\hline $\begin{array}{l}\text { - Provide an overview of the social issue/problem and relevant policy response that was } \\
\text { addressed in the group process } \\
\text { - Demonstrate logic of argument and provide evidence of analytical and critical } \\
\text { thinking } \\
\text { - Concise, succinct and consistent flow of ideas throughout }\end{array}$ & \\
\hline Small Group Discussion Facilitation & Grade \\
\hline $\begin{array}{l}\text { - Discussion is grounded in the literature related to the topic under discussion } \\
\text { - Critical analysis and synthesis of course concepts is evident } \\
\text { - Relevant life experiences, current events, and opinions of others are incorporated into } \\
\text { the group facilitation process that demonstrates a collaborative learning environment }\end{array}$ & \\
\hline Overall & Grade \\
\hline $\begin{array}{l}\text { - The topic is clearly delineated and focused } \\
\text { - Demonstration of team work in developing and presenting the } \\
\text { material } \\
\text { - Thoughtful and provocative group discussion } \\
\text { - Solutions presented are well formed, logical and realistic to address the problem }(s) \\
\text { identified }\end{array}$ & \\
\hline
\end{tabular}

